\title{
Consumer Ideology Determines Shopping Preferences at Farmers Markets in Two US Geographical Regions
}

\author{
Deanna Pucciarelli, Stacey Faith \\ Department of Family and Consumer Sciences, Ball State University, Muncie, USA \\ Email: dpucciarelli@bsu.edu
}

Received 15 August 2014; revised 12 September 2014; accepted 19 September 2014

Copyright $@ 2014$ by authors and Scientific Research Publishing Inc.

This work is licensed under the Creative Commons Attribution International License (CC BY).

http://creativecommons.org/licenses/by/4.0/

(c) (i) Open Access

\section{Abstract}

The purpose of this study was to identify if there were differences that existed in the behaviors, attitudes, awareness, and motivating factors that influenced people to shop at farmers' markets and purchase USDA certified organic food in two geographic regions: Corvallis, Oregon and Muncie, Indiana. A survey was administered to consumers who shopped at the Minnetrista Farmers' Market (MFM) and the Corvallis-Albany Farmers' Market (CAFM) in the summer of 2012 to measure the shoppers' purchasing perceptions. Specific areas of interest in this study included consumer values towards supporting local farmers and consuming USDA certified organic food. A comparison of responses between regions was analyzed. Results of the study provide insights on consumers' purchasing attitudes and behaviors regarding USDA certified organic products, and why they chose to shop at Farmers' Markets. Ideology was the strongest predictor for consumer purchasing behaviors. Understanding how regional differences affect food choice has implications for wellness programs and industry marketing materials.

\section{Keywords}

Consumer Choice, Farmers Market, Ideology, Geographic Region, Organic

\section{Introduction}

Fresh, quality, local, value-added agriculture and certified products all relate to organically produced food, a fast growing agricultural segment within the United States. Consumer demand for organically produced United States Department of Agriculture (USDA) certified goods has increased dramatically over the past few years, providing market incentives for farmers around the United States, especially for those selling directly to con- 
sumers [1]. Marketing efforts have increased organic food retail sales to \$21.1 billion in 2008 compared to \$3.6 billion in 1997 [2]. One direct to consumer exchange of organic goods is farmers’ markets. Since USDA's Agricultural Marketing Service began tracking farmers' markets in 1994, the number of markets in the United States had grown from 1755 to 8144 in 2013. The states with the highest concentration of farmers' markets include: California (759), New York (637), Illinois (336) and Michigan (331). Total annual sales at US farmers' markets are estimated at $\$ 1$ billion [3].

A question that arises for sellers of organic produce is: who is purchasing USDA certified organic foods? With the growth in popularity of attending farmers' markets and purchasing USDA certified organic foods it is important to know shoppers' motivations towards spending money on these products. Obtaining insight on this question is essential for the organic and farmers' market industries as it provides the opportunity for members to further maximize their profits by understanding who is buying their products so that they can target their marketing efforts. Developing a profile that identifies consumers who purchase organic food is the first step in defining this population, and what factors influence them to purchase organically.

Several studies have documented the demographic characteristics of consumers at farmers' markets who purchase USDA certified organic products. These include gender, age, education level, ethnicity, and annual household income. In a majority of these studies, Caucasian females with higher education and annual household incomes in the middle to higher distribution have positive association to purchasing USDA certified organic products while at the farmers' market. Consistently, the largest proportion of shoppers were married females who have earned an advanced degree and upper middle-class income, and who are in the middle to older age group [4]-[11]. Consumer age differentiated, but studies reported the majority population age ranged from thirty to sixty years old [4]-[6]. A majority of researchers [4]-[6] [12]-[16] have discovered similar demographic results of consumers that purchase USDA certified organic at farmers' markets.

A less studied, but equally as important influencing characteristic in consumer shopping behavior is ideology. Consumer preferences and attitudes are shaped, in part, by values, and like-minded groups tend to live in specific geographic regions. A national study was conducted that measured consumer preferences towards organic food purchases. The Hartman Group defined the participants as "heavy" or "light" buyers according to geographic location [17]. The Pacific region (including Oregon) had 22\% heavy buyers and 18\% light buyers, whereas the East North-central (including Indiana) had 13\% heavy buyers and 16\% light buyers. Identifying the underlying values these groups hold may correlate with specific purchasing behaviors.

The fact that Corvallis, Oregon and Muncie, Indiana are in two geographical parts of the United States could bring about diverse perception and motivating factors that may contribute to different purchasing decisions made between consumers. The USDA National Farmers' Market Manager Survey [18] compared a variety of differences between the regions of the United States, including the West and East North-central. Products labeled organic that were nationally sold at farmers' markets were more prevalent in the West (including Oregon) than in the East North-Central (including Indiana) region (74.5\% versus 39.8\%). The Hartman Group's national study on the organic consumer profile showed a low number of consumers purchasing organic products in the East North-Central compared to a high amount of consumers purchasing organic products in the west [17].

Identifying and comparing differences (i.e. purchasing behavior, attitude, and awareness) between Oregon and Indiana consumers may help identify why consumers are attending farmers' markets and purchasing USDA certified organic products in these two regions of the United States. It could be because there are more farmers' markets in the West versus the Midwest, or there could be more organically grown products available for consumers to purchase. This study's aims were to undercover the factors that influenced consumer purchasing behaviors in two geographic regions of the United States.

\section{Methods and Subjects}

\subsection{Pilot Study to Test Survey Instrument}

A pilot study was conducted at the Minnetrista Winter Farmers' Market, Indiana, February 2012. The survey used in this study was developed by modifying the consumers farmers' market surveys used in previous research studies [4] [5] [16] [19]-[24]. The survey included demographic questions, and questions about consumer behavior, attitude and motivating factors that influenced them to shop at farmers' markets and purchase USDA certified organic food. Also included were two qualitative questions. Both the quantitative and qualitative questions were sent to outside experts to measure external validity. Based on the results, a slightly modified survey in- 
strument was created.

\subsection{Subjects}

Subjects were residents of Corvallis, Oregon and Muncie, Indiana who visited the farmers' markets (CorvallisAlbany Farmers’ Market [CAFM] or Minnetrista Farmers’ Market [MFM]). Participants were 18 years or older, and both male and female. Exclusion criteria included non-residents. Residency was determined by the participants' zip codes. Zip code inclusion was determined by county where the two farmers' markets were located. In Oregon the county was Benton, and in Indiana, Delaware. Participants that did not have the appropriate zip code were excluded from analyses. A total of 102 and 106 participants attending began the survey and100 participants who shopped at the CAFM and MFM, respectfully, fully completed the survey. All participants met the residency criteria.

\subsection{Methods}

Permission was granted by Ball State University Institutional Review Board prior to study implementation. This study was approved as exempt by the Ball State University Institution Review Board on February 14, 2012.

\subsubsection{Survey Instrument}

The pilot study survey instrument was revised based on the pilot study participant responses. One question was removed because it did not solicit answers, and six questions were added to increase the depth of research findings. Cronbach's alpha was 0.788 for attitude and 0.726 for behavior. Three qualitative questions were added so consumers had more opportunity to expand on their quantitative responses. It was determined that the Motion LE-Series Slate Tablet PCs were unreliable. Instead, the Lenovo Netbooks were utilized for data collection utilizing the Qualtrics survey software package. Participants completed the Qualtrics survey on the Lenovo Netbooks, after which they would then answer five qualitative questions on the Olympus Digital Voice Recorder, WS-331M. The final quantitative survey instrument consisted of 35 questions.

\subsubsection{Data Collection}

The study was conducted at the CAFM in Corvallis, Oregon, June 2012, and at the MFM in Muncie, Indiana in July 2012. Both markets were open on Wednesday and Saturday. Surveys were administered at three Wednesday and Saturday market days at the CAFM, and three Wednesday and two Saturday market days at the MFM. Consumers were invited to complete the survey as they walked by the table set up at the farmers' markets main entrance.

The survey collection method was web-based. The primary investigator [PI] was assigned a location in the market that provided reliable signal strength on Saturdays, but with fewer vendors on Wednesdays the market location moved further from the Internet source. No internet connection was available on each of the Wednesday market days due to distance from the wireless signal. On Wednesdays, the survey was administered on paper. At the end of the Wednesday market days, the paper survey responses were entered by the PI into Qualtrics.

Once the respondents completed the survey, a series of five qualitative questions were asked, and the participants’ verbal responses were recorded. Each participant's Qualtrics ID was paired with the data. Each respondent's verbal response was labeled with a code, which was copied into the Excel spreadsheet, and then transcribed. This paired the qualitative response with the Qualtrics survey for each of the participants.

Word cloud diagrams were created from the qualitative responses with the web-based source, Wordle. These words were drawn from the constant comparative method, in that, repetitive responses were quantified, and themes were drawn from the most common answers. Words or phrases that appeared most frequently were summed for each qualitative question in an Excel spreadsheet. Once these were totaled, they were copied into Wordle to create the final Wordle diagram.

\subsubsection{Data Analyses}

Data were downloaded into IBM SPSS statistics v.19.0 for Windows (SPSS, 2011) for analyses. Descriptive statistics were tabulated, providing the mean, standard deviation, variance, and percentages for each of the survey questions. Pearson's Chi Square test was used to determine if there were significance differences between CAFM and MFM consumers. Significance was set at $\mathrm{p}<0.05$. 


\section{Results}

Demographic characteristics measured in this study included gender, age, household size, number of children in the household, education level, income, ethnicity, self-identified political affiliation, and zip code. Of the 100 participants from the CAFM, there were 66 (65\%) female and 36 (35\%) male (Table 1).

Eighty percent of CAFM and 83\% of MFM participants had no children under the age of 18 years. Fifty-five percent of CAFM and 44\% of MFM consumers had postgraduate or professional education. Thirty-nine percent of CAFM participants and 47\% of MFM participants had a household income of $\$ 25,001$ to $\$ 74,999$; whereas, $38 \%$ and $37 \%$, respectfully, were $>\$ 75,000$ (Table 1 ). A majority of both CAFM and MFM participants were Caucasian (89\% and 97\%, respectively). Seventy-nine percent of CAFM consumers had liberal to moderateliberal political views, whereas 43\% of MFM consumers had liberal to moderate-liberal political views. Eight percent of CAFM consumers had conservative to moderate conservative political views versus 36\% at the MFM. At CAFM, 66\% of participants lived in the 97330 Benton County zip code, and 58\% of MFM participants lived in the 47304 Delaware County zip code.

\subsection{Knowledge of USDA Organic Certification}

Farmers' market participants indicated common knowledge of organically grown produce requirements. When participants were tested on their knowledge of the USDA certified organic label, 59\% of CAFM and 56\% of MFM consumers indicated that verification is required by a USDA-accredited agent before a product can be labeled organic. When consumers were asked about the USDA certified organic labeling there was a statistical difference between CAFM and MFM consumers $\left(\chi^{2}=16.45, \mathrm{~N}=200, \mathrm{p} \leq 0.05\right)$. Forty-nine percent of CAFM participants knew "above average” the USDA certified organic label requirements, whereas 53\% of MFM consumers knew "below average”.

\subsection{Consumer Purchasing Behaviors and Attitudes}

Twenty-one percent of CAFM consumers and 41\% of MFM consumers indicated affordable prices as an important reason to shop at the farmers' markets. Convenience of shopping at farmers' markets was answered similarly among the CAFM and MFM consumers (37\% and 38\%, respectively). Forty-four percent of males and 33\% of females at CAFM indicated convenience as an important reason for shopping at farmers' markets. In contrast, only $27 \%$ of males at MFM indicated convenience as an important reason to shop at farmers' market versus $41 \%$ of the MFM female participants. Fifty-one percent of CAFM consumers and 40\% of MFM consumers indicated social gathering as a reason for shopping at farmers' markets.

Fifty-two percent of MFM consumers indicated that having organic products available at the farmers' market was unimportant compared to only 27\% at the CAFM (Table 2). Both CAFM and MFM consumers indicated having USDA certified organic products available at farmers' markets as unimportant, whereas there was a significant difference in opinions on having organic products (but not certified) available 31\% at the CAFM versus $17 \%$ at the MFM.

When there is a choice between USDA certified organic and non-organic products, 62\% of CAFM consumers and $38 \%$ of MFM consumers indicated they would choose organic $\left(\chi^{2}=12.58, \mathrm{~N}=200, p \leq 0.05\right)$. There was a significant difference between the farmers' market consumers when they have a choice between purchasing USDA certified organic and non-organic products $\left(\chi^{2}=10.18, \mathrm{~N}=208, p \leq 0.05\right)$. Forty-one percent of CAFM consumers indicated that price does not matter, with $31 \%$ of these consumers indicating that they would purchase USDA certified organic over non-organic products if it was a little more expensive. Only 29\% of MFM

Table 1. Demographic characteristics.

\begin{tabular}{|c|c|c|c|c|c|c|c|c|c|c|c|c|c|}
\hline & \multirow[b]{2}{*}{ Male } & \multirow[b]{2}{*}{ Female } & \multicolumn{3}{|c|}{ Age } & \multicolumn{3}{|c|}{$\begin{array}{l}\text { Children } \\
<18 \text { y/o }\end{array}$} & \multicolumn{3}{|c|}{ Education } & \multicolumn{2}{|c|}{ Income $^{2}$} \\
\hline & & & $\begin{array}{c}18-34 \\
y / 0\end{array}$ & $\begin{array}{c}35-64 \\
y / o\end{array}$ & $\begin{array}{l}65+ \\
\text { y/o }\end{array}$ & 0 & 1 & $2+$ & $\begin{array}{l}\text { High } \\
\text { School }\end{array}$ & College & $\begin{array}{c}\text { Post } \\
\text { College }\end{array}$ & $\begin{array}{c}\$ 25,001- \\
\$ 74,999\end{array}$ & $\$ 75,000+$ \\
\hline CAFM\% & 35 & 65 & 29 & 51 & 20 & 80 & 11 & 6 & 1 & 30 & 55 & 39 & 38 \\
\hline MFM\% & 25 & 75 & 25 & 51 & 24 & 83 & 12 & 5 & 9 & 32 & 44 & 47 & 37 \\
\hline
\end{tabular}

${ }^{1}$ not reported “some” college; ${ }^{2}$ Not all income percentages reported. 
consumers indicated that price does not matter when purchasing USDA certified organic over non-organic products. However, 31\% of MFM consumers indicated they would purchase USDA certified organic over nonorganic products if it is the same price.

CAFM consumers intentionally purchase USDA certified organic products for safety reasons (54\%), environmental reasons (52\%), and perceived as healthy food (50\%) (Figure 1). MFM consumers intentionally buy USDA certified organic food when shopping at the farmers' market for healthy food (33\%), freshness and quality (31\%), environmental reasons (25\%), and to help the local farmers (25\%). There was a statistical difference between the two farmers' market consumers in their belief that USDA certified organic food is safer than noncertified foods $\left(\chi^{2}=8.73, \mathrm{~N}=200, p \leq 0.05\right)$. Thirty-six percent of CAFM participants and 23\% of MFM participants indicated USDA certified organic foods as being safer than non-certified.

Consumers' responses were reviewed for emerging themes. The most common association among CAFM consumers was the term "local" used in association with geographical location (Figure 2), whereas MFM consumers associated "local" with the vendor (Figure 2). MFM consumers frequently indicated that produce appearance was a deciding factor when choosing which vendor to shop from. Only half of CAFM consumers indicated that produce appearance was a deciding factor when choosing which vendor to shop from. CAFM participants frequently indicated they came to the farmers' market for the atmosphere, whereas the MFM participants frequently indicated they came for the produce. MFM consumers were more concerned about the price when deciding which vendor to shop from compared to CAFM consumers. More CAFM participants indicated they

Table 2. Important reasons for shopping at the farmers' markets.

\begin{tabular}{|c|c|c|c|c|c|c|c|c|c|}
\hline & \multicolumn{3}{|c|}{ CAFM } & \multicolumn{3}{|c|}{ MFM } & \multirow[b]{2}{*}{$\chi^{2}$} & \multirow[b]{2}{*}{$d f$} & \multirow[b]{2}{*}{$p$} \\
\hline & 1 & 2 & 3 & 1 & 2 & 3 & & & \\
\hline & $\%$ & $\%$ & $\%$ & $\%$ & $\%$ & $\%$ & & & \\
\hline Variety of products available & 39 & 43 & 17 & 18 & 55 & 27 & 11.70 & 2 & 0.003 \\
\hline Low prices & 49 & 40 & 11 & 36 & 55 & 9 & 5.07 & 2 & 0.079 \\
\hline Organic products available & 27 & 41 & 31 & 52 & 31 & 17 & 13.60 & 2 & 0.001 \\
\hline Organically grown products are USDA certified & 63 & 29 & 8 & 67 & 27 & 6 & 0.60 & 2 & 0.740 \\
\hline Vendor is present & 40 & 41 & 18 & 18 & 57 & 26 & 12.68 & 2 & 0.002 \\
\hline Interacting with the vendor & 40 & 42 & 18 & 20 & 64 & 15 & 11.46 & 2 & 0.003 \\
\hline
\end{tabular}

Note: 1 = Unimportant; 2 = Neutral; 3 = Important.

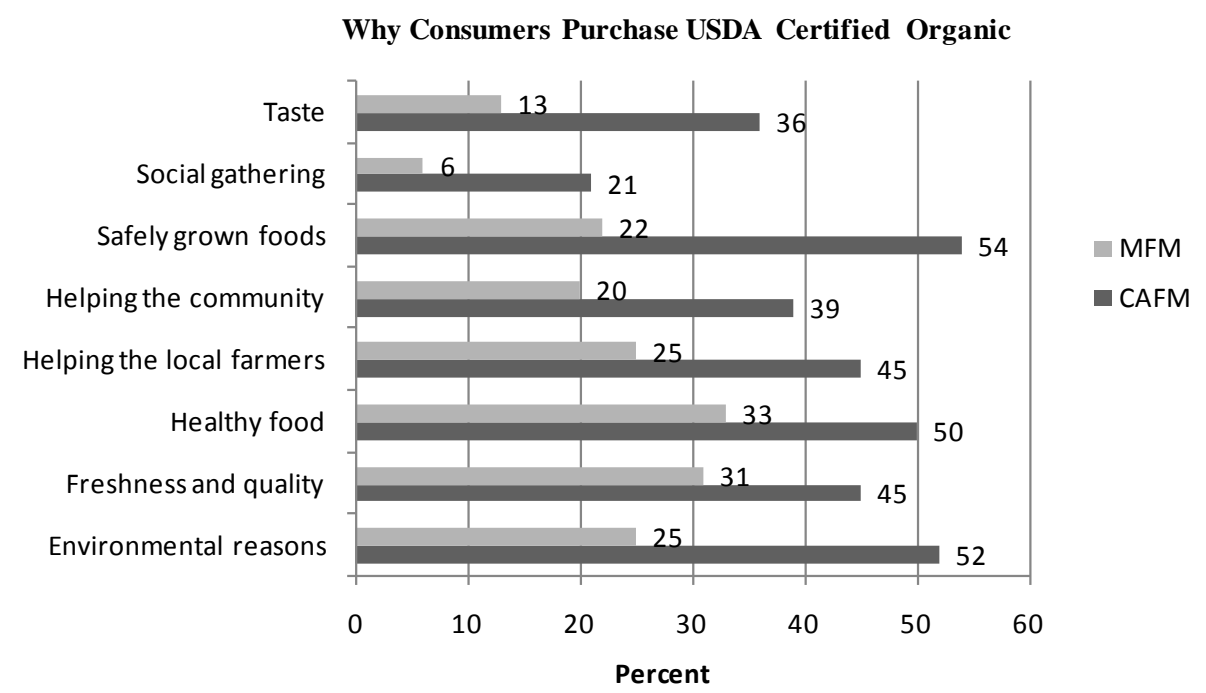

Figure 1. Reasons why consumers intentionally purchase USDA certified organic. 

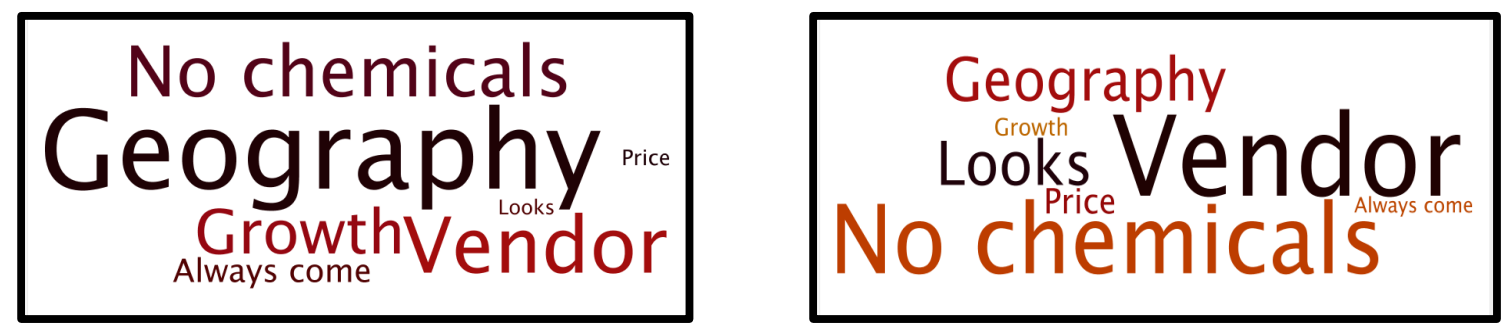

Figure 2. Emerging themes generated from CAFM (left) and MFM (right) consumers' responses pertaining to farmers' markets and USDA certified organic produce.

"always come” or that "It's Saturday!" when asked why they came to the farmers' market compared to the MFM participants. Overall production methods related to the produce was frequently stated by CAFM consumers compared to MFM consumers when questioned on what motivates them to purchase food at farmers' markets versus grocery stores. The produce, including freshness, quality, and taste, motivates MFM consumers to purchase food at the farmers' markets versus grocery stores.

According to the survey results, Oregon consumers have higher availability of organically grown products than Indiana consumers. The findings indicated that having organic products available at farmers' markets seemed to drive an increase in consumer spending and this in-line with previous findings [18].

\subsection{Consumer Demographics}

The consumers that attended the CAFM and MFM consisted of mostly Caucasian females with higher education levels that live in a household of two people with no children under the age of 18 years. The average age ranged between 25 to 64 years at the CAFM, and 35 to over 65 years at the MFM. Average household income for both farmers' market consumers was between $\$ 25,001$ and $\$ 74,999$. These findings are consistent with previous studies on the descriptions of farmers' market consumers that are purchasing USDA certified organic products [4]-[6] [12]-[16].

Political views among the two farmers' market consumers differed in that CAFM consumers had mostly liberal to moderate liberal views, whereas MFM consumers had conservative to moderate conservative views. Stephenson and Lev [25] stated that Corvallis, Oregon tend to be more liberal based on past voting behavior. According to recent election data provided by the Benton County Elections Office, $62 \%$ of Benton County, Oregon residents, where the CAFM is located, voted Democratic, where only 33\% voted Republican [26]. Forty-seven percent of Delaware County, Indiana residents, where the MFM is located, voted Republican where fifty percent voted Democrat [27].

\section{Discussion}

Demographic characteristics were consistent with previous research studies on farmers' market consumers that purchased USDA certified organic products [4]-[6] [12]-[16]. The consumers of the CAFM and MFM consisted mostly of female Caucasians with higher education levels that live in a two household setting with no children under the age of 18 years and an average household income between \$25,001 and \$74,999.

Consumer studies report farmers' market consumers' knowledge on USDA national standards and the familiarity of the term organic [16] [19] [22] [23] [25] [28]. A study conducted at an Oklahoma farmers' market indicated that $80 \%$ of consumers were "somewhat familiar" with the concept of organically grown produce [23]. Raab, et al. [22] studied Oregon food shoppers through phone interviews by randomly selecting households in Oregon. The participants were tested on their level of knowledge about the USDA National Organic Standards, which include standards for labeling foods as organic. Results indicated that 23\% of consumers knew "little”, 29\% knew "some", and 10\% knew "a lot" about these standards. These findings are consistent with the current study in that $29 \%$ of CAFM consumers indicated they knew "little" about the USDA certified organic label. However, there were more CAFM consumers, compared to the previous study on food shoppers that indicated they knew "some" (49\%) or "a lot" (14\%) about the USDA certified organic label. This could indicate that farmers' market consumers may have more knowledge on USDA certified organic labeling than general food shoppers in the state of Oregon. Additionally, 53\% of MFM consumers indicated they knew "little" about the USDA certified 
organic label, which is almost doubled compared to CAFM consumers. Only 33\% of MFM consumers indicated they knew "some" and 4\% indicated they knew "a lot" about the USDA certified organic label. This indicates that Oregon farmers' market consumers may have more knowledge regarding the USDA certified organic label than Indiana farmers' market consumers.

From the current study findings, more CAFM consumers indicated that they shop at the farmers' market for environmental reasons than MFM consumers. Oregon has significantly more organic farming agriculture compared to Indiana agriculture, which could explain this increased knowledge of CAFM consumers [17]. According to the 2007 Census of Agriculture data, the state of Indiana has a total of 287 farms and 14,143 acres of land used for organic production, with 239 of these farms that sell organic products [29]. Delaware County, where the MFM is located, has two farms that have organic productions, but acreage was withheld to avoid disclosing data for individual farms. According to the 2007 Census of Agriculture data [30], the state of Oregon has 933 organic farms and 92,405 acres of land used for organic production. Benton County, where the CAFM is located, has a total of 36 organic farms and 1912 acres of organic production. This data indicates that the CAFM consumers have more organic products to choose from since there are a large number of total farmers in Oregon compared to Indiana

In previous studies [16] [25] [28], socializing was one of the primary reasons shoppers attend farmers' markets. Lev, et al. [31], who studied Oregon and Idaho farmers' markets, indicated one of the primary reasons consumers are attracted to farmers' markets was because of the overall social atmosphere. In the current study, more CAFM and MFM women indicated that socialization was a factor that influenced them to shop at the farmers' market compared to CAFM and MFM men (data not shown). Additionally, more CAFM consumers, overall, indicated that socialization and atmosphere were factors that influenced them to shop at farmers' markets compared to MFM consumers. The majority of MFM consumers were attending the farmers' markets to purchase the products. These results indicate that CAFM consumers are more interested in shopping at the farmers' market for the social aspect, whereas MFM consumers shop mostly for the products. The CAFM was larger than the MFM on both Wednesday and Saturday market days, making it a larger event for consumers to attend. Visiting with friends and purchasing produce from the farmers' market seemed to be more of a valued activity for Oregon consumers than it was to Indiana consumers.

The availability of USDA certified organic products at the farmers' markets was mostly unimportant to both CAFM and MFM consumers (Table 2). Consumers emphasized a large amount of their organic farmers' market produce was Oregon Tilth certified. The Oregon Tilth Certified Organic [OTCR] [32] "provides a system that combines strict production standards, on-site inspections, and legally binding contracts to protect the producers and buyers of organic products”. Additionally, the OTCR works alongside the USDA National Organic Standards. With the OTCR providing the CAFM with certified produce, USDA certified products are not in high demand with these consumers. MFM consumers, however, do not have other certified products other than USDA certified organic products. These consumers may not have a high demand for USDA certified organic products, in general, due to their response of these products being unavailable at the farmers' market. Price, improper labeling, and lack of availability may affect consumer responses on USDA certified organic produce at farmers' markets [13] [33] [34]. These could all be factors that contribute to the MFM consumers' not finding organically grown products associated with USDA certification.

Researchers [35] that studied a Michigan farmers' market indicated that consumers attended the market in order to purchase food directly from the individual who grew it. However, a study conducted at the Corvallis, Oregon and Albany, Oregon farmers' market, consumers reported similar comments as the current study in that a small number of consumers found it valuable to know the producer. Having the vendor present was more important to MFM consumers than it was the CAFM consumers. Results may indicate that MFM consumers' desire to speak with the vendor in order to make a connection and contribution to the local economy.

Stephenson and Lev's [25] study on Oregon farmers' market consumers indicated that consumers defined the term "local" as products grown or processed within a 50 mile radius. Wolf, et al. [16] found that locally grown food was a "moderately desirable" characteristic of farmers' market consumers, indicating that having local produce available adds value at the farmers' markets. Jekanowski, et al. [34] survey on Indiana consumers' purchasing behavior indicated there was a strong willingness to purchase local produce. In the current study, a common theme generated among the CAFM consumers associated "local" products with geographical location, whereas MFM consumers associated "local" products with the vendor (Figure 2). Common indications that CAFM consumers associated with the growth of "local" products include the following: within the six-county 
region, in Willamette Valley, in Benton County, or within a certain mileage from the farmers' market (i.e. 100mile radius, 50-mile radius, 30-mile radius, and 25-mile radius). With Oregon residents concerned more with environmental outcomes than Indiana, these results are consistent with CAFM consumers focusing the term "local" on geographical location versus the vendor. MFM consumers, however, indicated associations of "local" produce to the vendor including the following: grown by local farmers', the method of growing and the processing of produce.

\section{Conclusions}

Determining consumers' motivating factors at farmers' markets and purchasing behaviors toward USDA certified organic products is essential to determine differences among farmers' market consumers in both Oregon and Indiana; therefore, regionalism can be used as a marker for consumer behavior. More CAFM consumers indicated that they knew "a lot" about USDA certified organic products whereas more MFM consumers indicated they knew "little" or "some". Having more knowledge and awareness of USDA certified organic products could be influencing CAFM consumers to shop at farmers' markets more frequently, and purchase local, organically grown produce more often.

The results of this study are encouraging in that some MFM consumers did have a little knowledge about USDA certified organic foods. This may indicate that more advertising for fact-based information on the growing procedures of fresh, locally grown produce could be essential for consumers of Delaware County. The MFM does not have a certification program such as Oregon Tilth. This indicates that even though CAFM consumers do not have high demand for USDA certified organic produce, they still have a variety of Oregon Tilth certified organic produce available.

Overall, the CAFM consumers commonly visited the farmers' market for socialization and atmosphere whereas MFM consumers came mostly to purchase produce. The results indicate that the CAFM is used as both a space for sociability and a place to purchase local produce whereas the MFM is used mostly as a non-sociable event where consumers can purchase local produce. CAFM consumers may view visiting the farmers' market as a way of life. They attend the farmers' market to be around other consumers with similar views, which motivates them to frequently attend the market. Qualitative responses of CAFM consumers frequently indicated they attend the farmers' market because "it is fun" and "to visit with friends". MFM consumers, however, frequently indicated they attend the farmers' markets "to buy produce", "to eat breakfast", and "trying to eat healthier". The data from this study indicates that CAFM consumers shop more frequently at the farmers' market than MFM consumers. There are clear differences and preferences in the various regions indicating that either social or industry marketing efforts to increase organic fruit and vegetable consumption needs to be region based rather than national.

\section{Acknowledgements}

The authors acknowledge and thank the participants from the CAFM and MFM, and both market managers. This study was funded in part by a Ball State University graduate assistance academic research grant. The authors report no conflict of interest.

\section{References}

[1] Greene, C. and Kremen, A. (2003) US Organic Farming in 2000-2001: Adoption of Certified Systems. Agriculture Information Bulletin No. 780, United States Department of Agriculture, Washington DC.

[2] Dimitri, C. and Oberholtzer, L. (2009) Marketing US Organic Foods: Recent Trends from Farms to Consumers. United States Department of Agriculture, Washington DC.

[3] Agicultural Marketing Resource Center (2012) Farmers Markets and Local Food Marketing. http://www.agmrc.org/markets_industries/food/farmers-markets

[4] Govindasamy, R., Zurbriggen, M., Italia, J., Adesoji, A., Nitzsche, P., et al. (1998) Farmers’ Markets: Consumer Trends, Preferences, and Characteristics. United States Department of Agriculture, Washington DC.

[5] Rainey, R., Crandall, P.G., O’Bryan, C.A., Ricke, S.C., Pendleton, S.S., et al. (2011) Marketing Locally Produced Organic Foods in Three Metropolitan Arkansas Farmers' Markets: Consumer Opinions and Food Safety Concerns. Journal of Agricultural \& Food Information, 12, 141-153. http://dx.doi.org/10.1080/10496505.2011.563223

[6] Zepeda, L. (2009) Which Little Piggy Goes to Market? Characteristics of US Farmers’ Market Shoppers. International 
Journal of Consumer Studies, 33, 250-257. http://dx.doi.org/10.1111/j.1470-6431.2009.00771.x

[7] Zepeda, L., Chang, H.S. and Leviten-Reid, C. (2006) Organic Food Demand: A Focus Group Study Involving Caucasian and African-American Shoppers. Agriculture and Human Values, 23, 385-394. http://dx.doi.org/10.1007/s10460-006-9001-9

[8] Zepeda, L. and Deal, D. (2009) Organic and Local Food Consumer Behaviour: Alphabet Theory. International Journal of Consumer Studies, 33, 697-705. http://dx.doi.org/10.1111/j.1470-6431.2009.00814.x

[9] Zepeda, L. and Leviten-Reid, C. (2004) Consumers’ Views on Local Food. Journal of Food Distribution Research, 35, 1-6.

[10] Zepeda, L. and Li, J. (2006) Who Buys Local Food? Journal of Food Distribution Research, 37, 385-394.

[11] Zepeda, L. and Li, J.H. (2007) Characteristics of Organic Food Shoppers. Journal of Agricultural and Applied Economics, 39, 17-28.

[12] Brown, C. (2003) Consumers' Preferences for Locally Produced Food: A Study in Southeast Missouri. American Journal of Alternative Agriculture, 18, 213-224. http://dx.doi.org/10.1079/AJAA200353

[13] Conner, D., Colasanti, K., Ross, B.R. and Smalley, S.B. (2010) Locally Grown Foods and Farmers Markets: Consumer Attitudes and Behaviors. Sustainability, 2, 742-756. http://dx.doi.org/10.3390/su2030742

[14] Crandall, P.G., Friedly, E.C., Patton, M., O’Bryan, C., Gurubaramurugeshan, A., Seideman, S., Ricke, S.C. and Rainey, R. (2010) Estimating the Demand for Organic Foods by Consumers at Farmers' Markets in Northwest Arkansas. Journal of Agricultural \& Food Information, 11, 185-208. http://dx.doi.org/10.1080/10496505.2010.491999

[15] Kremen, A., Greene, C. and Hanson, J. (2002) Organic Produce, Price Premiums, and Eco-Labeling in US Farmers' Markets. USDA Economic Research Service, Washington DC, 43-53.

[16] Wolf, M.M., Spittler, A. and Ahern, J. (2005) A Profile of Farmers' Market Consumers and the Perceived Advantages of Produce Sold at Farmers’ Markets. Journal of Food Distribution Research, 36, 192-201.

[17] The Hartman Group (2000) The Organic Consumer Profile. Bellevue, 49.

[18] USDA-AMS (2006) USDA National Farmers Market Manager Survey. Washington DC.

[19] Hozyash, K. (2009) Consumer Perceptions of the Connection between Food Production and Climate Change at Fiver Farmers' Markets in North Carolina. Nicholas School of the Environment, Duke University, Durham, 50.

[20] Lev, L. and Stephenson, G. (1998) Analyzing Three Farmers’ Markets in Corvallis and Albany, Oregon. Oregon State University Extension Service.

http://smallfarms.oregonstate.edu/sites/default/files/publications/techreports/TechReport2.pdf

[21] Dues, A.M. (2009) US College Student Perceptions of Organic Food Products and Buying Habits. Agriculture Education and Communication Department, California Polytechnic State University, San Luis Obispo, 49.

[22] Raab, C. and Grobe, D. (2005) Consumer Knowledge and Perception about Organic Food. Journal of Extension, 43. http://www.joe.org/joe/2005august/rb3.php

[23] Kerr Center for Sustainable Agriculture (2011) Farmer' Markets: Surveys of Oklahoma Producers, Managers, and Customers. Poteau.

[24] Curtis, K.R. (2008) Conducting Market Research Using Primary Data. University of Nevada. http://ag.arizona.edu/arec/wemc/nichemarkets/07conductingmarketresearch.pdf

[25] Stephenson, G. and Lev, L. (2004) Common Support for Local Agriculture in Two Contrasting Oregon Communities. Renewable Agriculture and Food Systems, 19, 210-217. http://dx.doi.org/10.1079/RAFS200481

[26] Benton County Elections Office (2012) Benton County Unofficial Election Results. http://www.co.benton.or.us///elections/results-general.php

[27] Delaware County, I.C.C.s.O. (2012) Voting and Elections. http://dcelectionday.com/DelawareCountyGeneralElection2012.pdf

[28] Conner, D.S., Montri, A.D., Montri, D.N. and Hamm, M.W. (2009) Consumer Demand for Local Produce at Extended Season Farmers’ Markets: Guiding Farmer Marketing Strategies. Renewable Agriculture and Food Systems, 24, 251259. http://dx.doi.org/10.1017/S1742170509990044

[29] USDA (2009) 2007 Census of Agriculture: Indiana State and County Data. N.A.S. Service, Washington DC.

[30] USDA (2009) 2007 Census of Agriculture: Oregon State and County Data. N.A.S. Service, Washington DC.

[31] Lev, L., Brewer, L. and Stephenson, G. (2003) Research Brief: Why People Attend Farmers’ Markets. O.S. Farms, Oregon State University Extension Service, Corvallis. http://smallfarms.oregonstate.edu/sites/default/files/publications/techreports/TechReport15.pdf

[32] OTCO (2012) Oregon Tilth Certified Organic. http://tilth.org/certification 
[33] Aryal, K.P., Chaudhary, P., Pandit, S. and Sharma, G. (2009) Consumers’ Willingness to Pay for Organic Products: A Case from Kathmandu Valley. Journal of Agriculture and Environment, 10, 15-26.

[34] Jekanowski, M.D., Williams II, D.R. and Schiek, W.A. (2000) Consumers’ Willingness to Purchase Locally Produced Agricultural Products: An Analysis of an Indiana Survey. Agricultural and Resource Economics Review, 29, 43-53.

[35] Smalley, S. (2009) Organic Products at Michigan Farmers’ Markets.

http://www.michiganorganic.msu.edu/uploads/files/31/susansmalley.pdf 
Scientific Research Publishing (SCIRP) is one of the largest Open Access journal publishers. It is currently publishing more than 200 open access, online, peer-reviewed journals covering a wide range of academic disciplines. SCIRP serves the worldwide academic communities and contributes to the progress and application of science with its publication.

Other selected journals from SCIRP are listed as below. Submit your manuscript to us via either submit@scirp.org or Online Submission Portal.
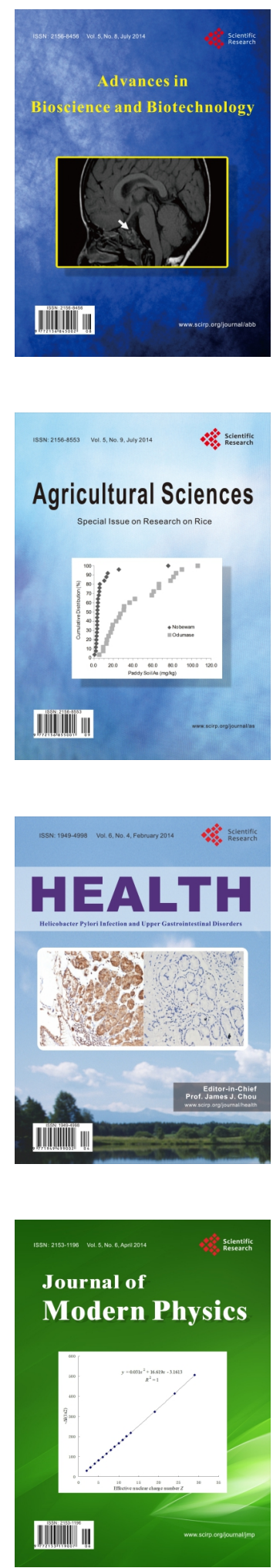
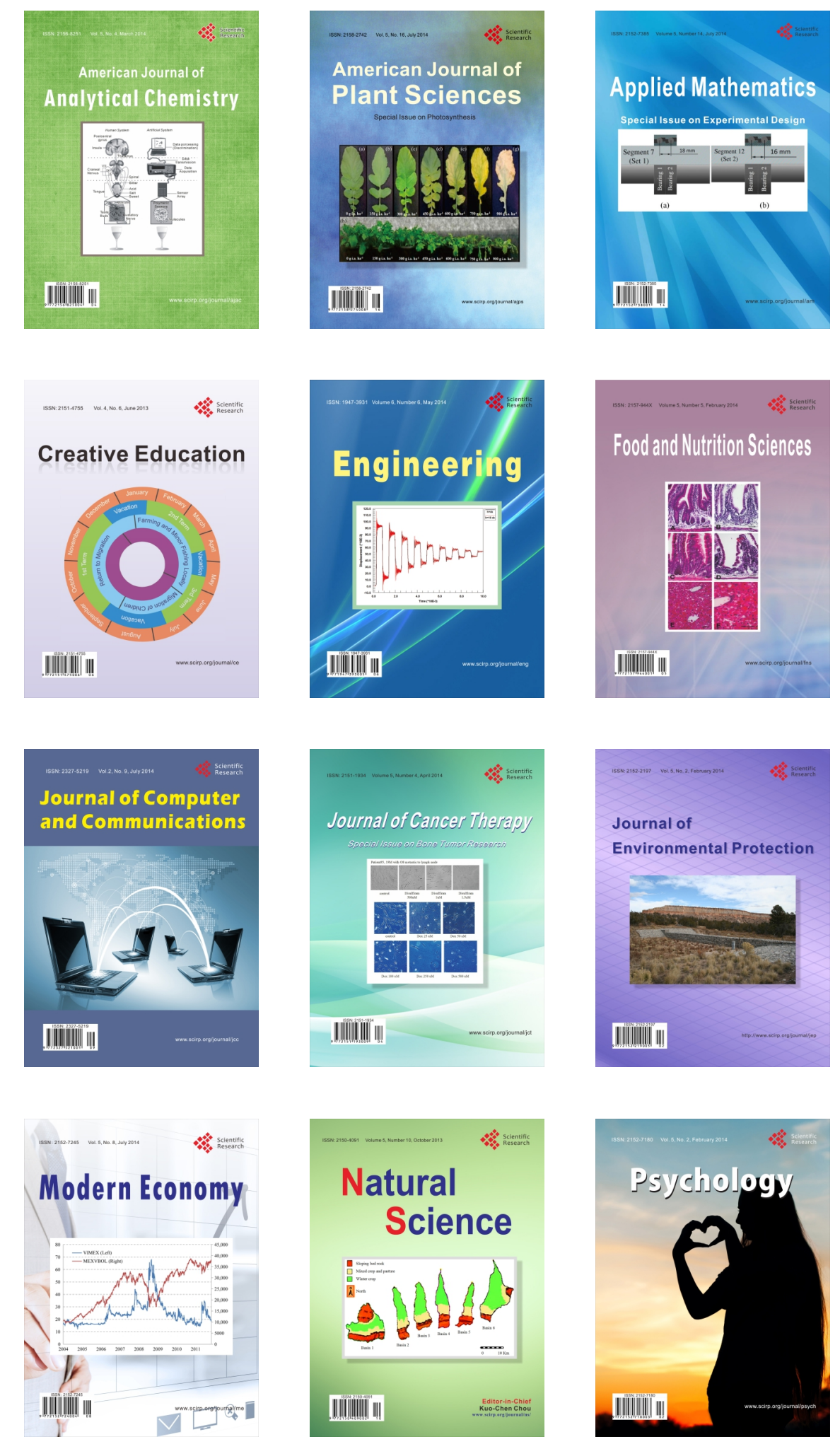